\title{
Awareness of using Radiology in Diagnosing COVID-19 among Radiological
} Students

\author{
Adnan A.S. Alahmadi ${ }^{\star}$ \\ Rawan H. Abdeen² (D)
}

${ }^{1,2}$ Department of Diagnostic Radiography Technology, College of Applied Medical Science, King Abdulaziz University (KAU), Jeddah, Saudi Arabia.

Email:aaalahmadi@kau.edu.sa

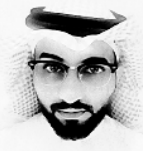

( Corresponding Author)

\begin{abstract}
The coronavirus (COVID-2019) has spread very rapidly over many countries around the world, producing an outbreak of acute infectious pneumonia. Medical imaging devices play a vital role in early diagnosis, evaluating severity and disease prognosis of confirmed patients with COVID-19. The aim of the study is to evaluate the awareness level of radiology students about COVID-19 and their understanding of the role of radiology devices in diagnosing COVID-19. An online cross-sectional questionnaire was conducted. Seventy-one students participated in this study. This study showed that students were properly aware of the basic knowledge of the COVID-19, $87 \%$ of the students believed that radiology had an important role in diagnosing COVID-19. In addition, $50 \%$ of the students believed that $\mathrm{CT}$ was the most important modality in diagnosing COVID-19 and 32.35\% believed that x-ray was the most important one. Lack of knowledge was found regarding the biomarkers that appear in radiological images in patients with COVID-19. $66.18 \%$ of the students acquired the knowledge from their study in the radiology field and from social media (Twitter). The level of awareness among radiology students is high. There were two main reasons for this high level of awareness: gained education and social media, especially Twitter. The outbreak of the COVID-19 was not only about its health effects but also how the population persevered this pandemic. However, this level of awareness tended to be lower when discussing detailed findings of radiological images such as detailed biomarkers.
\end{abstract}

Keywords: Radiological students, COVID-19, Awareness, Radiology, Education, Knowledge.

Citation | Adnan A.S. Alahmadi; Rawan H. Abdeen (2021). Awareness of using Radiology in Diagnosing COVID-19 among Radiological Students. Journal of Education and e-Learning Research, 8(1): 34-41.

History:

Received: 5 October 2020

Revised: 2 November 2020

Accepted: 18 December 2020

Published: 30 December 2020

Licensed: This work is licensed under a Creative Commons

Attribution 3.0 License (c) E:

Publisher: Asian Online Journal Publishing Group
Acknowledgement: Both authors contributed to the conception and design of the study.

Funding: This study received no specific financial support.

Competing Interests: The authors declare that they have no conflict of interests.

Transparency: The authors confirm that the manuscript is an honest, accurate, and transparent account of the study was reported; that no vital features of the study have been omitted; and that any discrepancies from the study as planned have been explained.

Ethical: This study follows all ethical practices during writing.

\section{Contents}

1. Introduction

2. Material and Methods ........36

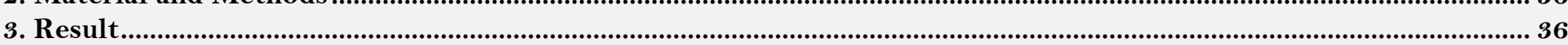

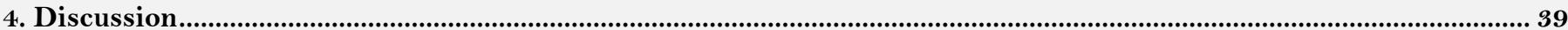

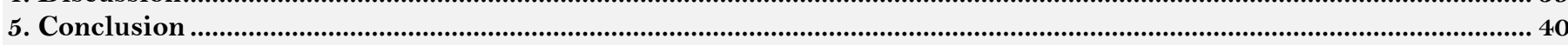

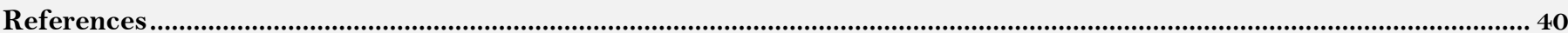




\section{Contribution of this paper to the literature}

This paper contributes to literature by offering an understanding of the awareness level of radiology students about COVID-19 and their understanding of the role of radiology devices in diagnosing COVID-19. This level of understanding and the gained knowledge was showing to be affected by self-directed sources such as social media. The usage of social media accounts could be directed in a way that could help increase the level of awareness among radiographers especially students.

\section{Introduction}

In late 2019, a cluster mysterious pneumonia cases termed coronavirus disease 2019 (COVID-19) was first discovered in the city of Wuhan, Hubei Province of the People's Republic of China (Fu et al., 2020). All the initial documented cases which characterized common symptoms including dry cough, fever, headache, fatigue, and occasional gastrointestinal symptoms occurred in the Huanan Seafood Wholesale Market in China (Wu, Chen, \& Chan, 2020). The disease was later spread to the whole world, causing a global health emergency and pandemic that affects the health and economy of the people around the world (An et al., 2020a). The number of reported cases increased sharply and by 17 June 2020, there were more than 8,043,487 confirmed cases, including 439,487 deaths worldwide (World Health Organization, 2020b). Since there are no specific vaccines or treatments for COVID-19, early diagnosis will allow isolating infected people immediately which is crucial to prevent the spread of disease, improve prognosis and decrease mortality (Esposito et al., 2020). Therefore, early diagnosis of COVID-19 is imperative to provide the appropriate health care (Fu et al., 2020).

Medical imaging devices play a vital role in early diagnosis, evaluating the severity and disease prognosis of confirmed patients with COVID-19 (Fu et al., 2020). With the rising numbers of COVID-19 cases, radiology staff, interns, and students must be aware of the radiological finding in all imaging modalities. Different radiological devices have been used to diagnose COVID-19 patients including x-ray, Computed tomography (CT), Ultrasound (US), and Magnetic Resonance Imaging (MRI) (Bd, Osei-Poku, \& Brakohiapa, 2020; Poggiali et al., 2020; Vasilev et al., 2020; Zhao et al., 2020). All these devices have been used to evaluate the early diagnosis and confirm cases as well as to investigate the associated complications of the disease.

Chest imaging is crucial for the diagnosis and management of COVID-19 cases (Li et al., 2020). For patients with suspected COVID-19, chest x-ray (CXR) was the first-line of image modality as it is cheap, easily available, and can be cleaned easily (Bd et al., 2020). The radiographic appearance of COVID-19 on CXR is atypical pneumonia (Kooraki, Hosseiny, Myers, \& Gholamrezanezhad, 2020). However, CXR is insensitive for the early stages of the COVID-19 and negative results do not rule out the disease (Dennie et al., 2020). However, CXR could be performed to create the baseline and follow-up for the progress of the disease (Czawlytko, Hossain, \& White, 2020).

Computed tomography (CT) images of the chest demonstrate high sensitivity with greater special resolution and faster scanning time in diagnosing COVID-19 patients (Zhao et al., 2020). CT is capable to identify changes in the lung tissue that are difficult to identify by CXR (Zhao et al., 2020). The results of the CT scan are often positive in patients with confirmed COVID-19 who had persistent fever, dry cough, and unexplained weakness (Pan \& Guan, 2020). Initial CT finding varies and includes lung ground glass shadow, local consolidation in the center surrounding with ground glass density, and pulmonary consolidation and nodules (Pan \& Guan, 2020). Researchers found that chest CT outperformed reverse-transcription polymerase chain reaction tests in diagnosing COVID-19 patients (Ai, Yang, \& Xia, 2020; Zhu et al., 2020). Therefore, chest CT is considered the initial screening method for screening and diagnosing of COVID-19 in China (Zhao et al., 2020).

Lung ultrasound (LUS) is another imaging modality that demonstrates its ability to characterize peripulmonary lesions observed in early and progressive COVID-19 patients, and these are greatly correlated with CT findings (Poggiali et al., 2020). The radiological findings of patients with COVID-19 in the LUS are several forms of B-lines, irregular pleural line, subpleural consolidates and pleural effusions (Peng, Wang, \& Zhang, 2020; Volpicelli, Lamorte, \& Villén, 2020). LUS might be performed as an additional imaging method without replacing the CT scan (Huang et al., 2020).

In case of limited availability of the CT, lung magnetic resonance image (MRI) can be used as a non-ionizing, alternative scanning technique for patients with COVID-19 (Vasilev et al., 2020). Crazy-paving pattern on MRI is clearly visualized and consistent with CT images (Vasilev et al., 2020). Lung MRI can assess the severity of the disease and the volume of the pulmonary lesion (Vasilev et al., 2020). MRI has been also used to evaluate the associated brain damaged and effects caused by the disease (Kremer et al., 2020).

In addition, since imaging plays an important role in diagnosing patients with suspected or confirmed with COVID-19, radiology staff are at great risk of infections with COVID-19 (Yu et al., 2020). It is important, therefore, to apply, and understand, the best practices of infection control and prevention in radiology departments to minimize the spread of infection and protect radiology staff (Yu et al., 2020). Personal protective equipment should be put on and take off in strict orders and these guidelines and awareness should be also highly known and appreciated by interns and students who must learn the appropriate technique to help to improve their knowledge and practices.

Given the above information and knowledge about COVID-19 and how radiology plays a vital role in assessing it as well as the level of precautions needed to be understood and taken, it is important to raise and understand the level of awareness among radiological staff, especially radiological students. This level of awareness is crucial to be fully studied and understood. It is also important to understand the gained sources of awareness whether from their studies, self-learning, or social media.

The latter is one of the primary sources of information to improve the awareness, knowledge, and practices of people (Karasneh, Al-azzam, Muflih, Soudah, \& Hawamdeh, 2020). This is especially the case as nowadays social media is the main channel delivering updated information about COVID-19 even though sometimes the source of information is not trusted for updates regarding the pandemic (Gao et al., 2020). In fact, false information may spread misinformation (Hamouche, 2020) thus it is important to assess as well the impact of the social media on the 
students' knowledge. Thus, the present study aimed to evaluate the awareness level of radiology students about COVID-19 and their understanding of the role of different radiology devices in diagnosing COVID-19 patients. In addition, the objective of this study was to assess their knowledge about infection control as well as the impact of social media on improving their awareness level. To the best of the authors' knowledge, this is the first study directly exploring radiology students' awareness and practice regarding this topic that will help develop an appropriate education program that creates awareness among future students.

\section{Material and Methods}

The target population of the study was the radiology students and intern in Jeddah, Saudi Arabia without inclusion or exclusion criteria of the target population. Utilizing a cross-sectional research design, this study examined the knowledge of radiology students about COVID-19, in addition to their awareness and practices of the role of radiology devices in diagnosing COVID-19 patients. A google form questionnaire was carried out between $5^{\text {th }}$ April and $12^{\text {th }}$ April 2020. All the information was collected through an online technique. 80 students participated in this study and before data analysis, 12 students were excluded as they were in a non-radiology field which left to a total of 68 participants. All participants gave informed consent and participated in the study using their free time. The questionnaire was sent via different channels electronically and local institutional ethical approval was sought.

The self-structured questionnaire was designed to acquire information on demographic characteristics, knowledge, and awareness of COVID-19 and radiology. The questionnaire was structured based on information drawn from the literature on the role of different radiology devices in diagnosing CO (Pan \& Guan, 2020; Peng et al., 2020). It contained 18 questions and classified into four sections: 1 general knowledge question about COVID19; 10 questions about different imaging modalities in and their roles in diagnosing COVID-19; 1 question related to the infection control practices for COVID-19; 6 questions about the role of social media in acquiring their knowledge. Proper statistics were performed using Microsoft excel and google sheets.

\section{Result}

A total of 68 radiology students responded to the online questionnaire. Most of the participants were from the age group of $18-24$ years $(n=66,97 \%)$. The demographic characteristics of the participants are demonstrated in Table 1. The students had a significant high knowledge about COVID-19 (92.65\%), approximately $87 \%$ of the students believed that radiology has an important role in diagnosing COVID 19 and in following up on patients who have COVID19 Table 2. The students were asked about their general knowledge of the different radiology devices; more than $51(75 \%)$ were aware of each radiology device Figure $1.50 \%$ of the students believed that CT was the most important modality in diagnosing COVID-19 while $32.35 \%$ believed that x-ray was the most important one Figure 2. When comparing radiological diagnosis to different medical diagnostic methods used in diagnosing COVID-19, students chose $88.24 \%$ for laboratory tests, $86.76 \%$ for radiology, $20.59 \%$ for biology, and $19.12 \%$ for epidemiology. However, $72.06 \%$ believed that laboratory test was the most important one to be used in diagnosing COVID-19 followed by $25 \%$ and $2.94 \%$ for radiology and biology respectively.

Table 3 demonstrated that the students responded to rate different statements about using different imaging modalities in relation to patients with COVID-19. Some of the basic biomarkers that appeared in radiological imaging were also assessed in Table 4. Most of the students were not sure about all these biomarkers in Table 4 . When asking the students about the time that these biomarkers will appear in images, $41.18 \%$ thought that the radiological modalities could detect these biomarkers on radiological images two weeks after the patients became infected, while $23.53 \%$ thought it could be detected immediately in images once the patients were diagnosed with COVID-19. Most of the students were aware of the infection precaution that should be taken when dealing with COVI-19 patients such as surgical mask (64.71\%), gowns (66.18\%), gloves (67.65), eye protection (61.76\%), and N95 mask $(63.42 \%)$ Table 5. The students were asked about the different sources of their information about the role of the radiology and its relation to COVID-19, $66.18 \%$ of the students had the knowledge from their study in the radiology field and from social media (Twitter) as shown in Figure 4. When we asked the students about the most valuable source that they used to increase their knowledge about COVID-19, 36.75\% mentioned Twitter, 32.35\% chose to research, $20.59 \%$ came from their study materials, $4.41 \%$ selected TV and WhatsApp, and $1.47 \%$ from newspapers. $82.35 \%$ of the students chose sometimes when we asked if they trust the scientific information from the social medial while only $10.29 \%$ answered yes and $7.35 \%$ do not trust the social media at all. In addition, $37 \%$ of the students trust the scientific information if it was presented by an organization account Figure 5 .

Table-1. Demographic characteristics of the radiology students.

\begin{tabular}{l|c|c}
\hline Demographic data & Number & Percentage (\%) \\
\hline Gender & & \\
\hline Male & 16 & $23.53 \%$ \\
\hline Female & 52 & $76.47 \%$ \\
\hline Age (year) & & \\
\hline $18-24$ & 66 & $97 \%$ \\
\hline $25-32$ & 1 & $1.50 \%$ \\
\hline $33-40$ & 1 & $1.50 \%$ \\
\hline $41-50$ & - & - \\
\hline Above 50 & - & - \\
\hline Year of radiology school & & \\
\hline Second-year & 31 & 45.58 \\
\hline Third-year & 9 & 13.23 \\
\hline Fourth-year & 7 & 10.3 \\
\hline Intern & 21 & 30.89 \\
\hline
\end{tabular}


Table-2. Responses of the participants regarding basic knowledge of COVID-19.

\begin{tabular}{l|c|c|c}
\hline Questions & Number responded Yes (\%) & $\begin{array}{c}\text { Number responded } \\
\text { No (\%) }\end{array}$ & $\begin{array}{c}\text { Number responded } \\
\text { Maybe (\%) }\end{array}$ \\
\hline $\begin{array}{l}\text { Do you know what COVID-19 or the } \\
\text { new coronavirus is }\end{array}$ & $63(92.65)$ & - & $5(7.35)$ \\
\hline $\begin{array}{l}\text { Do you think radiology has an } \\
\text { important role in diagnosing COVID } \\
19\end{array}$ & $59(86.76)$ & - & $9(13.24)$ \\
\hline $\begin{array}{l}\text { Do you think that radiology has a role } \\
\text { in following up on patients who have } \\
\text { COVID19 }\end{array}$ & $59(86.76)$ & $1(1.47)$ & $8(11.77)$ \\
\hline
\end{tabular}

Ultrasound

Nuclear Medicine

75

\subsection{4}

$X-R A Y$

97.06

CT

83.82

MR

77.94

Fluoroscopy

76.47

Figure-1. Knowledge of the students about different image modalities as expressed in percentage (\%).

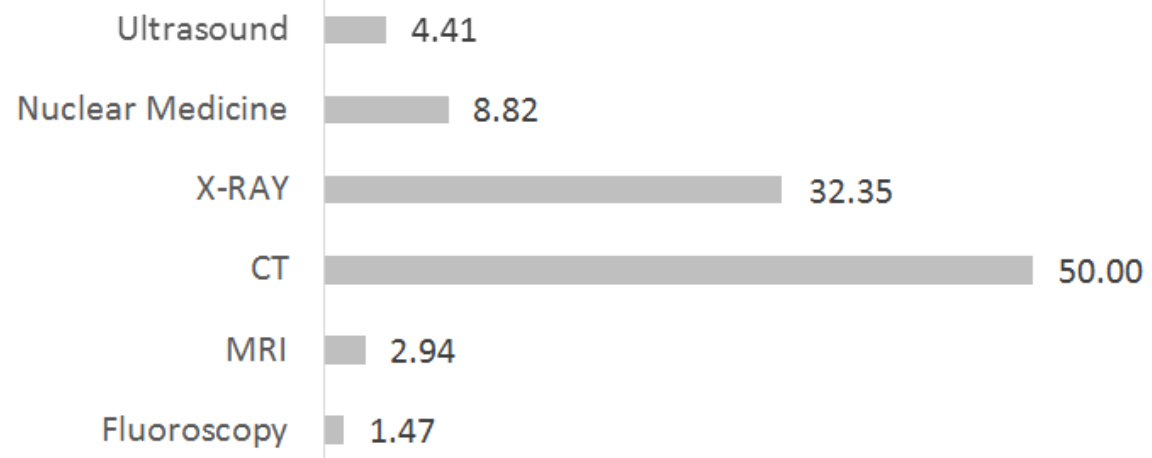

Table-3. Students response to rate the following statements in relation to patients with COVID-19.

\begin{tabular}{|c|c|c|c|c|c|}
\hline $\begin{array}{l}\text { Rate these statements in relation to patients } \\
\text { with COVID-19 }\end{array}$ & $\begin{array}{l}\text { Strongly } \\
\text { Agree } \\
\text { N }(\%)\end{array}$ & $\begin{array}{l}\text { Agree } \\
\mathrm{N}(\%)\end{array}$ & $\begin{array}{l}\text { Not sure } \\
\text { N (\%) }\end{array}$ & $\begin{array}{c}\text { Disagree } \\
\mathbf{N}(\%)\end{array}$ & $\begin{array}{c}\text { Strongly } \\
\text { disagree } \\
\mathrm{N}(\%)\end{array}$ \\
\hline $\begin{array}{l}\text { CT is the best modality to diagnose COVID } 19 \\
\text { compared to X-RAY }\end{array}$ & $31(45.59)$ & $19(27.94)$ & $11(16.18)$ & $5(7.35)$ & $2(2.94)$ \\
\hline $\begin{array}{l}\text { X-ray is my first option to start diagnosing } \\
\text { COVID } 19 \text { in the radiology department }\end{array}$ & $29(42.65)$ & $19(27.94)$ & $15(22.06)$ & $3(4.41)$ & $2(2.94)$ \\
\hline $\begin{array}{l}\text { X-ray is the best modality to diagnose COVID } \\
19 \text { compared to CT }\end{array}$ & $12(17.65)$ & $9(13.24)$ & $21(30.88)$ & $20(29.41)$ & $6(8.82)$ \\
\hline $\begin{array}{l}\text { MRI has no role in terms of diagnosing COVID } \\
19\end{array}$ & $12(17.65)$ & $12(17.65)$ & $29(42.65)$ & $11(16.18)$ & $4(5.88)$ \\
\hline $\begin{array}{l}\text { All patients with COVID } 19 \text { show abnormal } \\
\text { radiological findings }\end{array}$ & $24(35.29)$ & $24(35.29)$ & $20(29.41)$ & $5(7.35)$ & $4(5.88)$ \\
\hline $\begin{array}{l}\text { Radiological Imaging alone is enough to } \\
\text { diagnose patients with COVID } 19\end{array}$ & $5(7.35)$ & $6(8.82)$ & $15(22.06)$ & $22(32.35)$ & $20(29.41)$ \\
\hline $\begin{array}{l}\text { Ultrasound has no role in terms of diagnosing of } \\
\text { COVID } 19\end{array}$ & $13(19.12)$ & $16(23.53)$ & $29(42.65)$ & $5(7.35)$ & $5(7.35)$ \\
\hline $\begin{array}{l}\text { Portable X-ray is preferable than normal X-ray } \\
\text { in diagnosing COVID } 19\end{array}$ & $16(23.53)$ & $16(23.53)$ & $26(38.24)$ & $8(11.76)$ & $2(2.94)$ \\
\hline $\begin{array}{l}\text { If a patient has a severe respiratory illness but } \\
\text { the X-ray is normal, then the patient can be } \\
\text { advised to go home and the diagnosis is not } \\
\text { COVID } 19\end{array}$ & $6(8.82)$ & $10(14.71)$ & $19(27.94)$ & $11(16.18)$ & $22(32.35)$ \\
\hline $\begin{array}{l}\text { Abnormal Chest X-ray that shows signs of } \\
\text { COVID } 19 \text { is enough to diagnose a patient with } \\
\text { COVID } 19\end{array}$ & $10(14.71)$ & $6(8.82)$ & $21(30.88)$ & $18(26.47)$ & $13(19.12)$ \\
\hline $\begin{array}{l}\text { Abnormal Chest CT that shows signs of COVID } \\
19 \text { is enough to diagnose a patient with COVID } \\
19\end{array}$ & $15(22.06)$ & $16(23.53)$ & $16(23.53)$ & $14(20.59)$ & $7(10.29)$ \\
\hline $\begin{array}{l}\text { Radiological findings should be always } \\
\text { associated with laboratory tests for early } \\
\text { diagnosing of COVID } 19 \text { patients }\end{array}$ & $34(50.00)$ & $17(25.00)$ & $16(23.53)$ & $1(1.47)$ & - \\
\hline $\begin{array}{l}\text { Laboratory tests alone are enough to confirm } \\
\text { and diagnose COVID } 19 \text { patients }\end{array}$ & $12(17.65)$ & $18(26.47)$ & $26(38.24)$ & $10(14.71)$ & $2(2.94)$ \\
\hline $\begin{array}{l}\text { Early signs of COVID } 19 \text { can be detected using } \\
\text { radiological imaging }\end{array}$ & $12(17.65)$ & $18(26.47)$ & $27(39.71)$ & $8(11.76)$ & $3(4.41)$ \\
\hline
\end{tabular}


Table-4. Students' knowledge regarding some biomarkers that appear in radiological imaging in patients with COVID-19.

\begin{tabular}{l|c|c|c|c|c}
\hline $\begin{array}{l}\text { I have the knowledge that these } \\
\text { biomarkers appear in radiological } \\
\text { imaging in COVID 19 patients }\end{array}$ & $\begin{array}{c}\text { Strongly } \\
\text { Agree } \\
\mathbf{N}(\%)\end{array}$ & $\begin{array}{c}\text { Agree } \\
\mathbf{N}(\%)\end{array}$ & $\begin{array}{c}\text { Not sure } \\
\mathbf{N}(\%)\end{array}$ & $\begin{array}{c}\text { Disagree } \\
\mathbf{N}(\%)\end{array}$ & $\begin{array}{c}\text { Strongly } \\
\text { disagree } \\
\mathbf{N}(\%)\end{array}$ \\
\hline Ground glass opacities Bilateral & $15(22.06)$ & $19(27.94)$ & $31(45.59)$ & $3(4.41)$ & - \\
\hline Ground glass opacities Unilateral & $6(8.82)$ & $16(23.53)$ & $40(58.82)$ & $6(8.82)$ & - \\
\hline Air space Consolidation & $13(19.12)$ & $21(30.88)$ & $31(45.59)$ & $1(1.47)$ & $2(2.94)$ \\
\hline Broncho vascular thickening & $11(16.18)$ & $22(32.35)$ & $32(47.06)$ & $1(1.47)$ & $2(2.94)$ \\
\hline Pleural Effusion & $14(20.59)$ & $17(25.00)$ & $32(47.06)$ & $3(4.41)$ & $2(2.94)$ \\
\hline
\end{tabular}

After two weeks

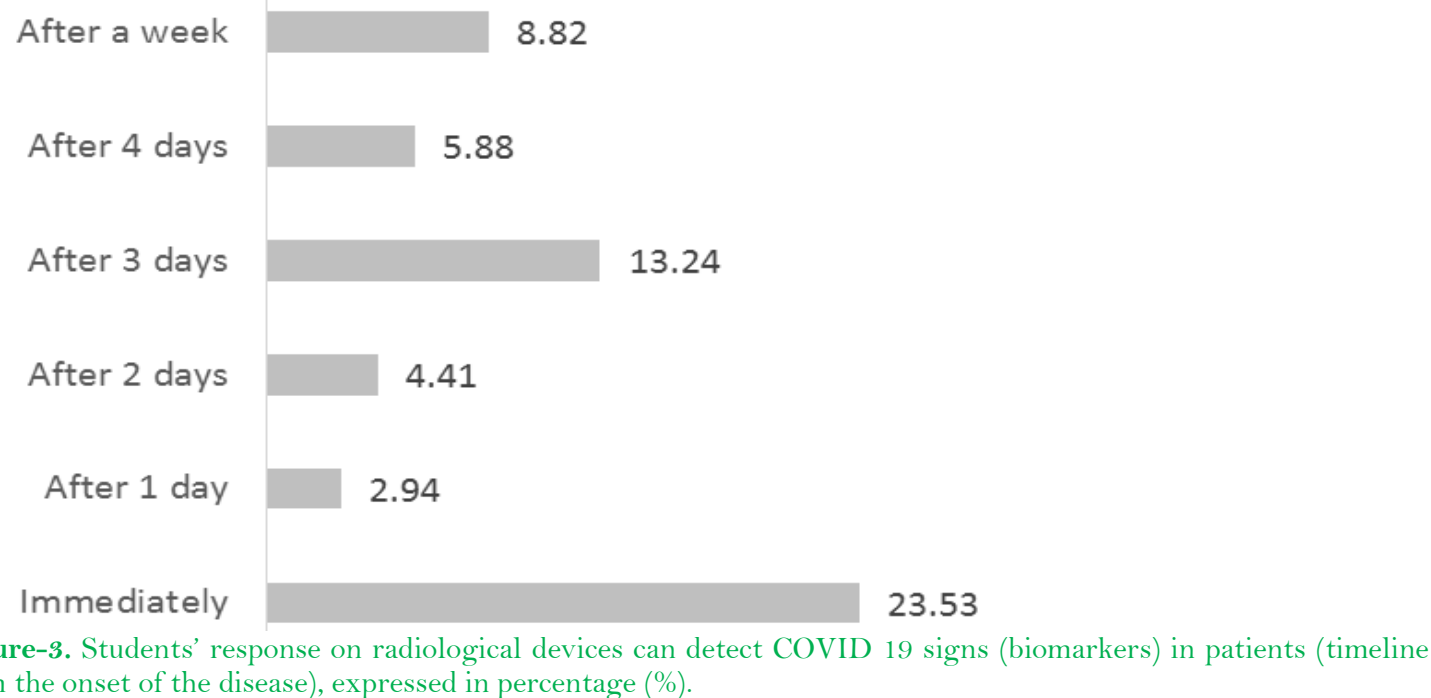

from the onset of the disease), expressed in percentage (\%).

Table-5. Students response to rate the following statements in relation to infection precautions when dealing with COVID-19.

\begin{tabular}{|c|c|c|c|c|c|}
\hline $\begin{array}{l}\text { Rate these statements related to infection } \\
\text { precautions when dealing with COVID } 19\end{array}$ & $\begin{array}{c}\text { Strongly } \\
\text { Agree } \\
\text { N (\%) } \\
\end{array}$ & $\begin{array}{l}\text { Agree } \\
\text { N (\%) }\end{array}$ & $\begin{array}{l}\text { Not sure } \\
\text { N }(\%)\end{array}$ & $\begin{array}{l}\text { Disagree } \\
\mathbf{N}(\%)\end{array}$ & $\begin{array}{c}\text { Strongly } \\
\text { disagree } \\
\text { N }(\%)\end{array}$ \\
\hline $\begin{array}{l}\text { Radiology staff are one of the first to be in contact } \\
\text { with COVID } 19 \text { patients }\end{array}$ & $30(44.12)$ & $19(27.94)$ & $14(20.59)$ & $4(5.88)$ & $1(1.47)$ \\
\hline $\begin{array}{l}\text { Infection control should be normal without any } \\
\text { additional cautions }\end{array}$ & $5(7.35)$ & $11(16.18)$ & $16(23.53)$ & $17(25.00)$ & $19(27.94)$ \\
\hline Wearing a medical mask is important & $44(64.71)$ & $12(17.65)$ & $8(11.76)$ & $4(5.88)$ & - \\
\hline Wearing medical gowns is important & $45(66.18)$ & $14(20.59)$ & $7(10.29)$ & $2(2.94)$ & - \\
\hline Wearing medical gloves is important & $46(67.65)$ & $11(16.18)$ & $9(13.24)$ & $2(2.94)$ & - \\
\hline Wearing medical eye protection is important & $42(61.76)$ & $12(17.65)$ & $11(16.18)$ & $2(2.94)$ & $1(1.47)$ \\
\hline Wearing medical mask (N95) is important & $43(63.24)$ & $11(16.18)$ & $13(19.12)$ & $1(1.47)$ & - \\
\hline $\begin{array}{l}\text { My precautions information was gained during } \\
\text { my study }\end{array}$ & $24(35.29)$ & $22(32.35)$ & $16(23.53)$ & $5(7.35)$ & $1(1.47)$ \\
\hline $\begin{array}{l}\text { My precautions information was gained from } \\
\text { social media }\end{array}$ & $16(23.53)$ & $23(33.82)$ & $15(22.06)$ & $8(11.76)$ & $6(8.82)$ \\
\hline $\begin{array}{l}\text { Social media and news has motivated me to either } \\
\text { work or volunteer in helping the medical sections }\end{array}$ & $18(26.47)$ & $20(29.41)$ & $22(32.35)$ & $7(10.29)$ & $1(1.47)$ \\
\hline
\end{tabular}

After two weeks

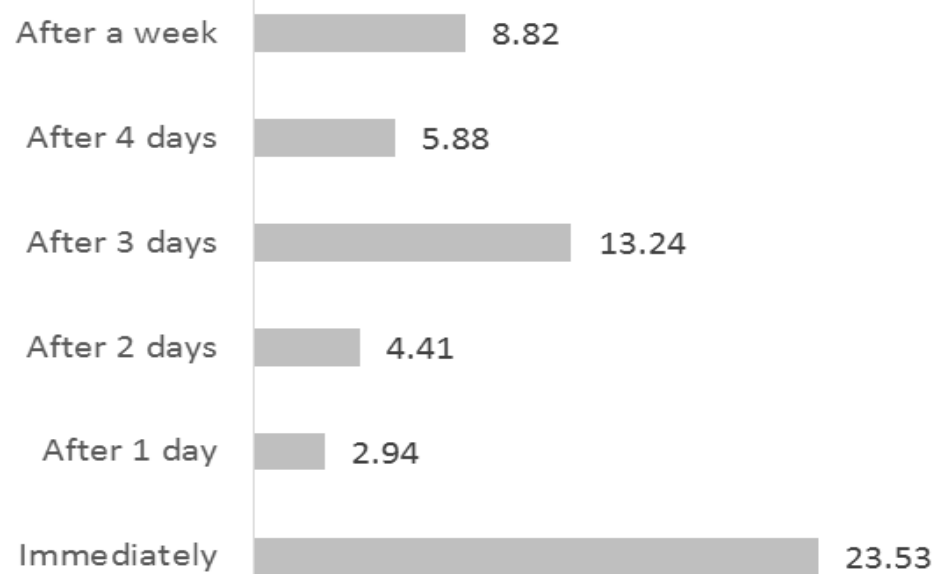

Figure-4. Students' response to the sources of their information about the role of radiology in COVID-19, as expressed in percentage (\%). 
Your study (Background)

Research (self interests in findings information)

News papers

TV

Social media (WhatsUp)

Social media (Snapchat)

Social media (Instagram)

Social media (Twitter)

10.29

Figure-5. Students' response to when they trust the social media account, as expressed in percentage (\%).

\section{Discussion}

From December 2019 the world has been facing an outbreak of COVID-19 caused by severe acute respiratory syndrome, which has spread rapidly to the whole world (An et al., 2020b). The World Health Organization considered this virus as a public health emergency (World Health Organization, 2020a). Diagnostic imaging has been giving significant radiological support for diagnosing this disease and prognosis prediction (Yantao, Junfang, Ziqiao, Xiao, \& Quanfu, 2020). Several radiological devices have been used to diagnose COVID-19 patients including x-ray, CT, US, and MRI (Bd et al., 2020; Poggiali et al., 2020; Vasilev et al., 2020; Zhao et al., 2020) and the awareness and appropriate knowledge about the role of these radiology devices in diagnosing COVID-19 are important for those who work directly with these devices or who study them. Therefore, this study aimed to evaluate the level of awareness (and its sources) of radiology students about COVID-19, specifically, the role of different radiology devices in diagnosing COVID-19 patients. Our study revealed that radiology students had good basic knowledge about COVID-19 and recognized the radiology devices that could be used during the diagnosis.

This high level of awareness among the radiology students could be explained and linked to their educational specialty in the field. Specifically, students tend to link their specialty to the status of the pandemic. Generally, it has been shown before that specialty usually tailor their specialty to whatever environment they are facing. Also, it seems that the growth and the impact of COVID-19 on people forced those students to engage using their own knowledge of understanding more about COVID-19 and radiology.

The finding of this study demonstrated that even though there was high knowledge about the basic role of radiology in diagnosing COVID-19, there was a low level of awareness regarding the details of biomarkers that appear in radiological imaging in patients with COVID-19. This was particularly about the unilateral of ground glass opacities. One possible explanation for this low level is the fact that coronavirus is a new virus that has not been previously identified, and those biomarkers have just been discovered. Thus, the students most probably did not know or study it before. Another possible explanation is that the sample of students who performed this study were only radiological technology students and the main part of their study is to operate diagnostic equipment, accurately position patients, perform the medical imaging examinations, and recognize only basic radiological pathologies. Deep details of the pathologies in images is usually recognized by radiologist whose main responsibility is to analyze and diagnose medical images (Pareek, 2018).

When diagnosing patients suspected with COVID-19, radiological imaging are the one of the first tests to be considered, and staff who work in the radiology department are facing high risk of COVID-19 exposures(Yu et al., 2020). Therefore, it is important to scrutinize the existing infection control and prevention practices in order to decrease cross-infection and protect healthcare professionals in the radiology department (Yu et al., 2020). The present study showed that most radiology students agree that it is important to wear protective masks, gown, gloves, and eye protection when dealing with COVID-19 patients. They showed great knowledge about essentials and detailed information about general and specific COVID-19 protections. This result seems to be consistent with other results from pharmacists who also showed positive attitudes towards wearing protective gear when dealing with COVID-19 patients (Karasneh et al., 2020). The high knowledge regarding the basic infection control could be due to their studying and background, especially with the expectations that they may face or be directly in touch with COVID-19 patients. As the knowledge about COVID-19 expands every day, it is important to continuously modify and update the infection control practices. The findings suggested it is important to release official guidelines of the infection control in radiology department to all radiology students during the pandemic to make sure that all students are aware and well informed of the best infection control practices.

In addition, high knowledge and awareness of radiology students about COVID-19 and the basic role of using radiology in treating with and diagnosing COVID-19 patients resulted from their background studies and social media platforms, especially Twitter. Several previous research studies found that social media could facilitate acquiring up to date available information which should improve awareness, knowledge, and practices of general public and health care professionals (Gralinski \& Menachery, 2020; Karasneh et al., 2020).

About $66.18 \%$ of the students' used social media specially Twitter as the main source for the information related to COVID-19. Even though traditional face-to-face teaching and learning represents the biggest part in education, Twitter demonstrated to be an efficient method for professional development and for cooperation with students that can alter the rule models of teaching strategy (Tang \& Hew, 2017). Probably the usage of Twitter as one of the most reliable sources of information chosen by students seem to be because the way this platform is structured (e.g., using written sentences). 
However, there are several sites and sources, which resulted in misinformation and difficulties to differentiate between reality and rumors (Karasneh et al., 2020). Therefore, people should seek trustworthy site for COVID-19 such as the WHO (Karasneh et al., 2020). This suggestion is in line with the findings of this study which showed that even though the highest percentage of the students used Twitter as the main source of their information, $82.35 \%$ chose sometimes (hesitating) when asked if they trust the scientific information from the social media, while only $10.29 \%$ answered yes and $7.35 \%$ did not trust social media at all. In addition, more than $50 \%$ of the students trust social media accounts if they are organization ones. Students' responses demonstrate a high level of awareness regarding using the trustworthy sources.

Future studies should compare the level of knowledge between the radiological biomarkers of COVID-19 and the biomarkers of other respiratory diseases. Did the increase in news, public fears, and level of precautions taken by higher authorities affected increasing this level of knowledge or not? The increased level of awareness about COVID-19 among students has many benefits, including findings the right source of information, increasing students' knowledge as well as improving self-learning. This knowledge should help as well increasing the awareness about other respiratory diseases, clinical and technical notes regarding radiology devices.

\section{Conclusion}

Radiology students have good awareness level about COVID-19 and the basic role of radiology in diagnosing it. This gained knowledge were significantly influenced by their education and their interaction using social media, especially Twitter. The study also identified that there was low level of awareness regarding the detailed pathological findings of radiological images such as different detected biomarkers. As the global threat of COVID19 continues to emerge, it is important to raise the awareness level of the radiology students and to do that this study started by determine this level. Educational campaigns are desired for radiology students, and further studies are needed. The usage of social media accounts should be more organized as it seems that most of the participants in this study engaged with them and accepted them as reliable sources of information.

\section{References}

Ai, T., Yang, Z., \& Xia, L. (2020). Correlation of chest ct and rt-pcr testing in coronavirus disease. Radiology, 1-23. Available at: https://doi.org/10.14358/PERS.80.2.000.

An, P., Ye, Y., Chen, M., Chen, Y., Fan, W., \& Wang, Y. (2020a). Management strategy of novel coronavirus (COVID-19) pneumonia in the radiology department: A Chinese experience. Diagnostic and Interventional Radiology Ankara, Turkey, 26(3), 200-203. Available at: https://doi.org/10.5152/dir.2020.20167.

An, P., Ye, Y., Chen, M., Chen, Y., Fan, W., \& Wang, Y. (2020b). Management strategy of novel coronavirus (COVID-19) pneumonia in the radiology department: A Chinese experience. Diagnostic and Interventional Radiology, 26, 200-203. Available at: https://doi.org/10.5152/dir.2020.20167.

Bd, S., Osei-Poku, K., \& Brakohiapa, E. (2020). Diagnosing COVID-19 from chest X-ray in resource limited environment-case report. In iMedPub Journal, 6(1). Available at: https://doi.org/10.36648/247 1-8041.6.2.135.

Czawlytko, C., Hossain, R., \& White, C. (2020). Covid-19 diagnostic imaging recommendations. Applied Radiology, 49(3), 10-15.

Dennie, C., Hague, C., Lim, R. S., Manos, D., Memauri, B. F., Nguyen, E. T., \& Taylor, J. (2020). The canadian society of thoracic radiology and canadian association of radiologists (car) consensus statement regarding chest imaging in suspected and confirmed covid-19. Canadian Association of Radiologists Journal, 1-22. Available at: https://doi.org/10.1177/0846537120924606.

Esposito, A., Palmisano, A., Scotti, G. M., Morelli, M. J., Vignale, D., Cobelli, F. D., . . Tacchetti, C. (2020). Why is chest CT important for early diagnosis of COVID-19? Prevalence Matters. MedRxiv. Available at: https://doi.org/10.1 101/2020.03.30.20047985.

Fu, F., Lou, J., Xi, D., Bai, Y., Ma, G., Zhao, B., . . Wang, M. (2020). Chest computed tomography findings of coronavirus disease 2019 (COVID-19) pneumonia. European Radiology, 2019. Available at: https://doi.org/10.1007/s00330-020-06920-8.

Gao, J., Zheng, P., Jia, Y., Chen, H., Mao, Y., Chen, S., . . Dai, J. (2020). Mental health problems and social media exposure during COVID19 outbreak. PLOS ONE, 15(4), 1-10. Available at: https://doi.org/10.1371/journal.pone.0231924.

Gralinski, L., \& Menachery, V. (2020). Return of the coronavirus: 2019-nCoV. Viruses, 12(135), 1-8. Available at: https://doi.org/10.3390/v12020135.

Hamouche, S. (2020). COVID-19 and employees' mental health: Stressors, moderators and agenda for organizational actions. Emerald Open Research, 2(15), 1-13. Available at: https://doi.org/10.35241/emeraldopenres.13550.1.

Huang, Y., Wang, S., Liu, Y., Zhang, Y., Zheng, C., Zheng, Y., . . Hu, M. (2020). A preliminary study on the ultrasonic manifestations of peripulmonary lesions of non-critical novel coronavirus pneumonia (COVID-19). Infecutious Disease, 1-14.

Karasneh, R., Al-azzam, S., Muflih, S., Soudah, O., \& Hawamdeh, S. (2020). Media's effect on shaping knowledge, awareness risk perceptions and communication practices of pandemic COVID-19 among pharmacists. Reseach in Social and Administrative Pharmact, $20,1-6$. Available at: https://doi.org/doi.org/10.1016/j.sapharm.2020.04.027.

Kooraki, S., Hosseiny, M., Myers, L., \& Gholamrezanezhad, A. (2020). Coronavirus (COVID-19) outbreak: What the department of radiology should know. Journal of the American College of Radiology, 17(4), 447-45 1. Available at: https://doi.org/10.1016/j.jacr.2020.02.008.

Kremer, S., Lersy, F., de Sèze, J., Ferré, J.-C., Maamar, A., Carsin-Nicol, B., . . Cotton, P. F. (2020). Brain mri findings in severe covid-19: A retrospective observational study. Radiology, 1-18. Available at: https://doi.org/10.1148/radiol.2020202222.

Li, M., Lei, P., Zeng, B., LiZ., Yu, P., Fan, B., . . Liu, H. (2020). Coronavirus disease (COVID-19): Spectrum of CT findings and temporal progression of the disease. Academic Radiology, 27(5), 603-608. Available at: https://doi.org/10.1016/j.acra.2020.03.003.

Pan, Y., \& Guan, H. (2020). Imaging changes in patients with 2019-nCov. European Radiology. Available at: https://doi.org/10.1007/s00330020-06713-Z

Pareek, A. (2018). Staff and their responsibilities in radiology center. Cancer Therapy \& Oncology International Journal, 10(3), 1-3. Available at: https://doi.org/10.19080/CTOIJ.2017.10.555789.

Peng, Q. Y., Wang, X. T., \& Zhang, L. N. (2020). Findings of lung ultrasonography of novel corona virus pneumonia during the 2019-2020 epidemic. Intensive Care Medicine, 46(5), 849-850. Available at: https://doi.org/10.1007/s00134-020-05996-6.

Poggiali, E., Dacrema, A., Bastoni, D., Tinelli, V., Demichele, E., Ramos, P., . . Magnacavallo, A. (2020). Can lung us help critical care clinicians in the early diagnosis of novel coronavirus (covid-19). Pneumonia. Radiology, 295(3), 5-6. Available at: https://doi.org/10.1007/bfo2686389.

Tang, Y., \& Hew, K. F. (2017). Using twitter for education: Beneficial or simply a waste of time? Computers and Education 106, 97-118. Available at: https://doi.org/10.1016/j.compedu.2016.12.004.

Vasilev, Y., Sergunova, K., Bazhin, A., Masri, A., Vasileva, Y., Suleumanov, E., . . Morozov, S. (2020). MRI of the lungs in patients with COVID-19: Clinical case. MedRxiv. 1-13. Available at: https://doi.org/10.1 101/2020.05.13.20088732.

Volpicelli, G., Lamorte, A., \& Villén, T. (2020). What's new in lung ultrasound during the COVID-19 pandemic. Intensive Care Medicine, 912. Available at: https://doi.org/10.1007/s00134-020-06048-9.

World Health Organization. (2020a). Statement on the second meeting of the international health regulations (2005) emergency committee regarding the outbreak of novel coronavirus. World Health Organization. Available at: https://doi.org/10.34161/johta.2015.3.2.001.

World Health Organization. (2020b). WHO coronavirus disease (COVID-19) dashboard. Covid-19 Dashboard. Retrieved from: https://covid 19.who.int/. 
Wu, Y.-C., Chen, C.-S., \& Chan, Y.-J. (2020). The outbreak of COVID-19 -an overview. Journal of the Chinese Medical Association, 83(3), 217220. Available at: https://doi.org/10.1097/JCMA.0000000000000331.

Yantao, N., Junfang, X., Ziqiao, L., Xiao, L., \& Quanfu, S. (2020). Management of infection control and radiological protection in diagnostic radiology examination of COVID-19 cases. Radiation Medicine and Protection, 1, 75-80.

Yu, J., Ding, N., Chen, H., Liu, X. J., Pu, Z. H., Xu, H. J., . . Zhang, H. W. (2020). Loopholes in current infection control and prevention practices against covid-19 in radiology department and improvement suggestions. Canadian Association of Radiologists Journal, 1-7. Available at: https://doi.org/10.1177/0846537120916852.

Zhao, Y., Xiang, C., Wang, S., Peng, C., Zou, Q., \& Hu, J. (2020). Radiology department strategies to protect radiologic technologists against COVID19: Experience from wuhan. European Journal of Radiology, 127, 1-5. Available at: https://doi.org/10.1016/j.ejrad.2020.108996.

Zhu, N., Zhang, D., Wang, W., Li, X., Yang, B., Song, J., . . Tan, W. (2020). Use of chest ct in combination with negative rt-pcr assay for the 2019 novel coronavirus but high clinical suspicion. New England Journal of Medicine, 382(8), 727-733. Available at: https://doi.org/10.1056/NEJMoa2001017. 